\title{
Role of Herbal Medicines in Alzheimer's Disease
}

Address for Correspondence: Archana; dineshkumargndu@gmail.com

\begin{abstract}
Received:
01.03.2019

Accepted:

25.03.2019

Keywords

Alzheimer's

disease;

Cognitive

destruction;

Nootropic

actions.
\end{abstract}

\author{
Archana ${ }^{* 1}$, Pooja Sharma ${ }^{1,2}$, Dinesh Kumar ${ }^{1}$ \\ ${ }^{1}$ Sri Sai College of Pharmacy, Manawala, Amritsar-143115, Punjab, India \\ ${ }^{2}$ Department of Pharmaceutical Sciences and Drug Research, Punjabi University Patiala, Punjab, India
}

ABSTRACT: Alzheimer's disease (AD) is characterized by intense memory loss sufficient to interfere with social and occupational functioning. It is the most common form of dementia, affecting more than 20 million people worldwide. AD is characterized by a dangerous loss of memory, associated functional decline, and behavioral disturbances. Products from natural resources such as medicinal plants have been utilized for the treatment of various memory disorders like dementia and Alzheimer's. The systematic review of this article is identified herbs and herbal formulations with therapeutic effects for the treatment of AD which includes Melissa officinalis, Salvia officinalis, Bacopa monnieri and Chinese herb Yi Gan San. Ginkgo biloba was identified in a meta-analysis study. All these herbs are useful for cognitive destruction of AD. M. officinalis and $\mathrm{Yi}$-Gan San are also useful in agitation, but they have sedative effects as compare to other natural herbs. These herbs and formulations have established good therapeutic effectiveness. Traditionally, Bacopa monnieri was utilized for memory and cognitive function enhancement. Extracts of Bacopa monnieri has been extensively investigated for its neuropharmacological effects and nootropic actions. This review provides the description of different medicinal plants and the clinical effects of a number of commonly used types of herbal medicines for the treatment of AD. (C) 2019 iGlobal Research and Publishing Foundation. All rights reserved.

Cite this article as: Archana; Sharma, P.; Kumar, D. Role of Herbal Medicines in Alzheimer's Disease. Indo Global J. Pharm. Sci., 2019; 9(2Suppl.): 149. DOI: http://doi.org/10.35652/IGJPS.2019.92S47.

Indo Global Journal of Pharmaceutical Sciences( ISSN 2249 1023; CODEN- IGJPAI; NLM ID: 101610675) indexed and abstracted in CrossRef (DOI Enabling), UGC CARE Journal List, EMBASE(Elsevier), National Library of Medicine (NLM) Catalog, ResearchGate, Publons, CAS (ACS), Index Copernicus, Google Scholar and many more. For further details, visit http://iglobaljournal.com

This is a special issue as an outcome of 'RAPSCON-2019' sponsored by APTI and organized by Sri Sai College of Pharmacy, Manawala, Amritsar, Punjab, India. Relaxation offered in journal format. 